\title{
A Multi Input Multi Output Converter for Hybrid Energy Systems
}

\author{
T. Baldwin Immanuel' ${ }^{1}$ A. Suresh ${ }^{2 *}$, M. R. Rashmi ${ }^{3}$ \\ ${ }^{1}$ St. Peter's University, Chennai, India \\ ${ }^{2} \mathrm{~S}$. A. Engineering College, Chennai, India \\ ${ }^{3}$ Amrita Vishwa Vidyapeetham, School of Engineering, Bengaluru, India \\ Email: bimmanuelt@gmail.com, ${ }^{*}$ drsuresha@saec.ac.in, rashmi.power@gmail.com
}

Received 7 March 2016; accepted 8 May 2016; published 13 May 2016

Copyright (C) 2016 by authors and Scientific Research Publishing Inc.

This work is licensed under the Creative Commons Attribution International License (CC BY). http://creativecommons.org/licenses/by/4.0/

(c) $\underset{\mathrm{EY}}{\mathrm{B}}$ Open Access

\begin{abstract}
Multi input and multi output converters are becoming popular because they are cost effective and compact. This paper proposes a multi input multi output converter for Grid-Solar power integration for uninterrupted power supply. The proposed converter uses four winding transformer with two primary windings and two secondary windings. The grid supply is connected to the first winding of transformer through rectifier-inverter for controlled power transfer. The solar energy is inverted and applied to the second winding of primary. Two output ports are considered. The circuit is designed to get zero current switching during turn-off and zero voltage switching during turn-on to alleviate the switching losses. The simulation results for the proposed configuration are presented in this paper.
\end{abstract}

\section{Keywords}

Multi Input/Multi Output Converters, ZCS/ZVS, Grid-Solar Power Integration, Multi Winding Transformer

\section{Introduction}

The demand for uninterrupted, good quality power supply is the major challenge for the current hybrid energy systems. Integrated power converters are capable of interfacing and controlling energy sources concurrently [1] [2]. Multi input single output, multi input-multi output, single input-multi output converters were proposed for many applications. Multiport converters can be of isolate or non-isolated type. In isolated topologies, multiwinding transformers were employed to transfer the energy from the primary sides to the secondary sides with galvanic isolation provided between different ports. Several topologies proposed were based on flyback [3] [4]

${ }^{*}$ Corresponding author. 
and bridge [5]-[8] configurations. They were used for single input and multi-outputs. These isolated converters offer flexible voltage transformation and regulation, but the transformer adds on weight and cost. As an alternate for this, several isolated multi-output converters were proposed. Primarily buck, boost, SEPIC and Cuk-converter topologies were extended to get multi-outputs [9]-[15]. However, these topologies were designed for power supplies. To feed AC load, the solar power has to be converted to AC. The distributed energy system consisting of grid supply and solar power needs a transformer for integration. Two different inverter configurations were proposed in the literature for this type of distributed energy systems. The first configuration consists of two inverters, connected in parallel, whose outputs are connected to the grid through a multi-winding step-up transformer. The main drawback of this scheme is that it operates at low frequency, hence bulky transformer is required [16]-[20]. The second type is with multi input DC-DC converter cascaded with inverter for AC loads. This configuration offers galvanic isolation and high boosting capability, however; it consists of multiple power processing stages. Moreover, bulky electrolytic capacitors are required at the DC link. Electrolytic capacitors cause severe reliability issues in inverters. They are extremely sensitive to temperature and their life deteriorates due to increase in temperature. In fact, capacitor reliability is currently inadequate for PV inverters; therefore, it is necessary to support design of alternative inverter topologies to simplify and reduce the cost of inverters while increasing their reliability. A multiport high frequency AC link inverter as the interface among the photovoltaic (PV) modules, battery energy storage system, and three-phase AC load was proposed in [21].

This paper proposes two-output ports converter topology for connecting PV supply and Grid supply through galvanic isolation. The proposed converter uses four winding transformer with two primary windings and two secondary windings. The grid supply is connected to the first winding of transformer through rectifier-inverter for controlled power transfer. The solar energy is inverted and applied to the second winding of primary. Two output ports are considered. The circuit is designed to acieve zero current switching during turn-off and zero voltage switching during turn-on to alleviate the switching losses. Section 2 describes the proposed configuration; Section 3 gives simulation results and analysis and the Conclusion is given in Section 4.

\section{Proposed Configuration}

The circuit diagram of the proposed topology is shown in Figure 1. Single phase supply from grid is rectified. The rectifier current is smoothened by filter inductor Lgf and the voltage is smoothened by the filter capacitor Cgf.

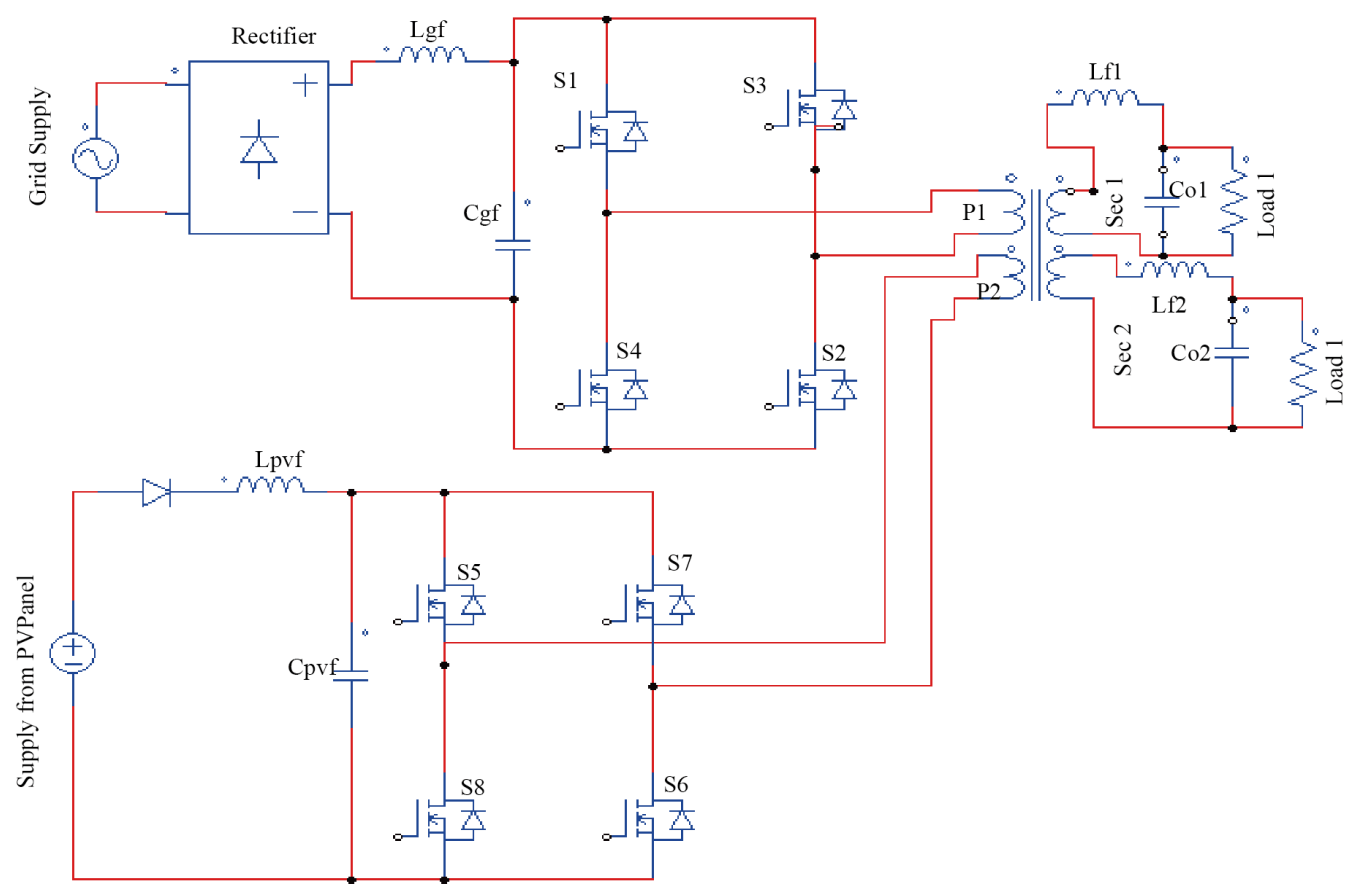

Figure 1. Proposed configuration. 
The rectified voltage is fed to inverter 1 consisting of switches S1-S4. The inverted output is given to Transformer primary P1. Load 1 is connected to the first secondary Sec1. The LC filter Lf1 and Co1 are used to shape the output voltage to a sine wave.

The second input is from PV Panel. The ripples in current and voltage are minimized by using filter inductor Lpvf and Cpvf respectively. This stiff DC supply is converted to AC by using an inverter consisting of switches S6-S8. This inverter output is given to second primary winding P2 of the transformer. Load 2 is connected to second winding of secondary through the filter inductor Lf2 and filter capacitor Co2. The LC filters in secondary in addition to shaping the secondary voltages, will also helps in attaining zero voltage and zero current switching of all the inverter switches.

\section{Simulation Results}

The simulation is carried out in PSIM environment. The simulation circuit is shown in Figure 2. The simulation parameters are listed in Table 1.

The switching pulses, voltage across the switch and swicth currents for S1 \& S2 are shown in Figure 3. For switches S3 \& S4, they are shown in Figure 4. The switching pulses, voltage across the switch and swicth currents for S5 \& S6 are shown in Figure 5 and for the switches S7 \& S8 shown in Figure 6.

It is observed from Figures 4-6, that for all the switches. The current through switches is zero during turn-on, voltage across switch is zero at the instant when turn-off is initiated as shown in Figure 7. Hence Zero current zero voltage switching is achieved. This soft switching will alleviate the switching losses.

The two primary voltages Vp1 and Vp2 are shown in Figure 8. The two secondary voltages are shown in Figure 9.

The load 1 and load 2 voltages are shown in Figure 10 and Figure 11 respectively. The output voltages are sinusoidal. Load 1 has a peak voltage of $210 \mathrm{~V}$ and load 2 has peak voltage of $115 \mathrm{~V}$.
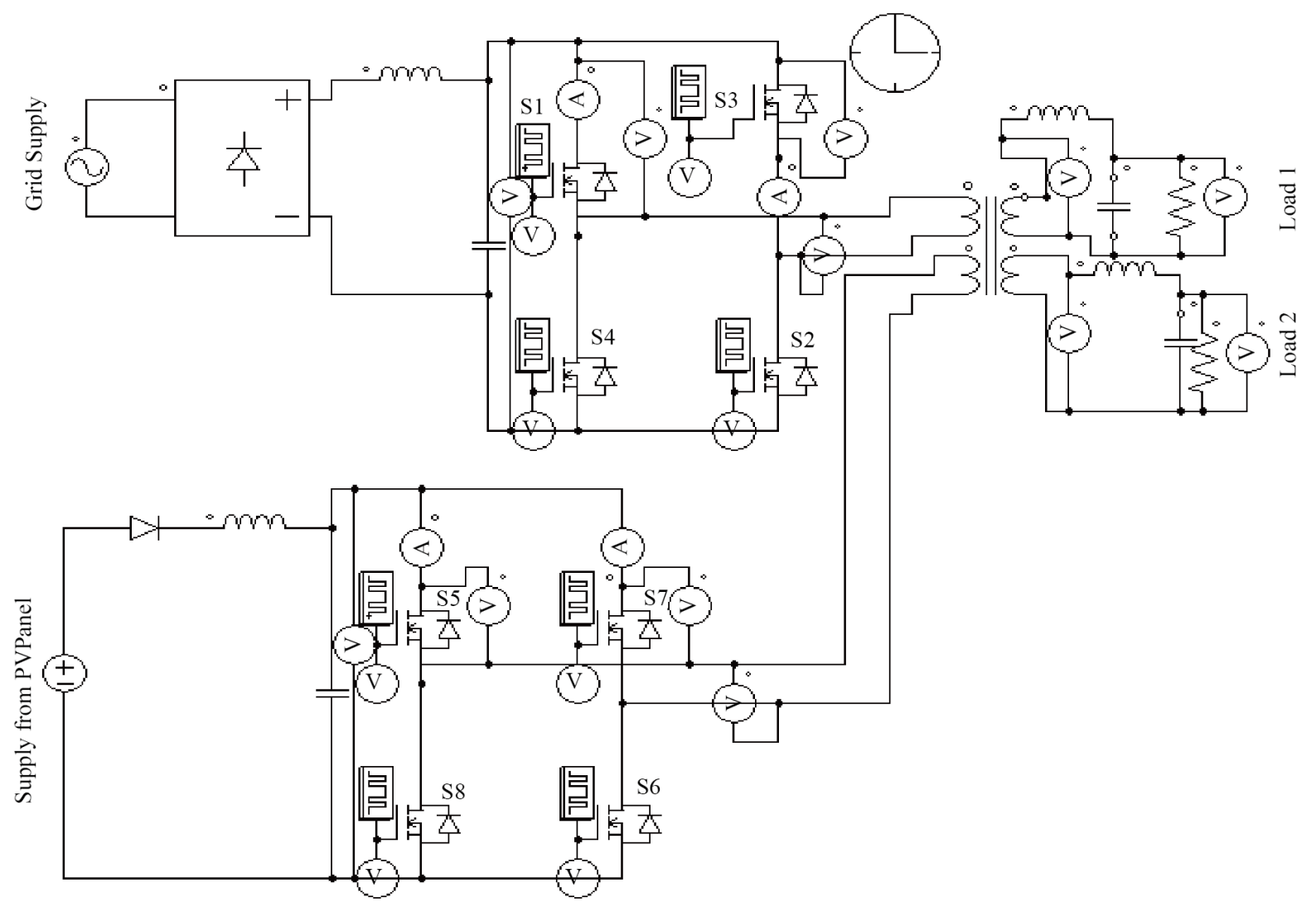

Figure 2. Simulation circuit. 

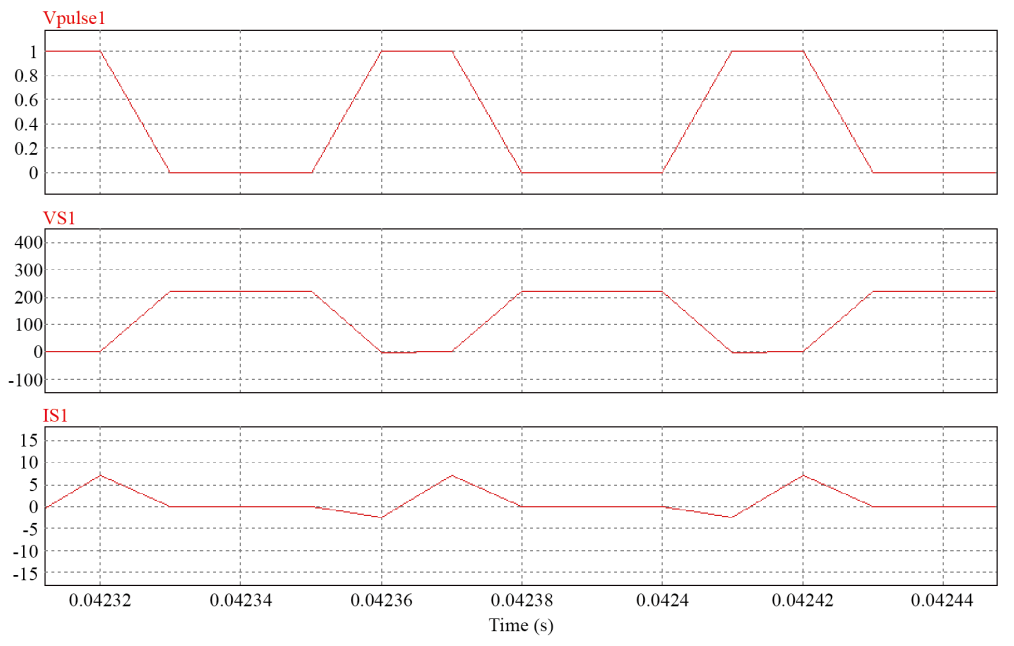

Figure 3. The switching pulses, voltage across the switch and swicth currents for S1 \& S2.
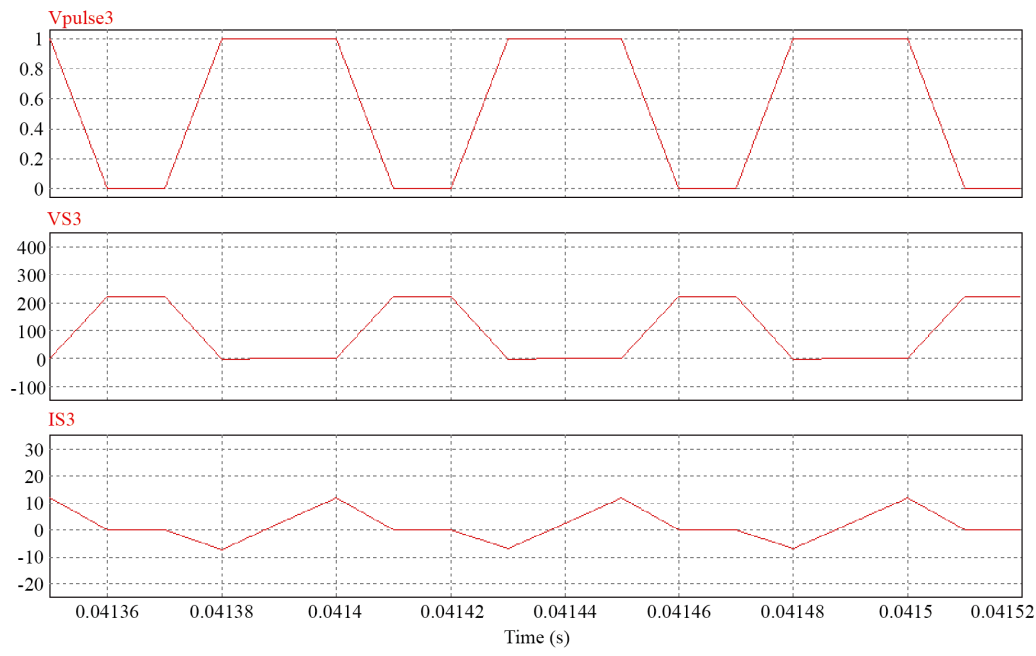

Figure 4. The switching pulses, voltage across the switch and swicth currents for S3 \& S4.
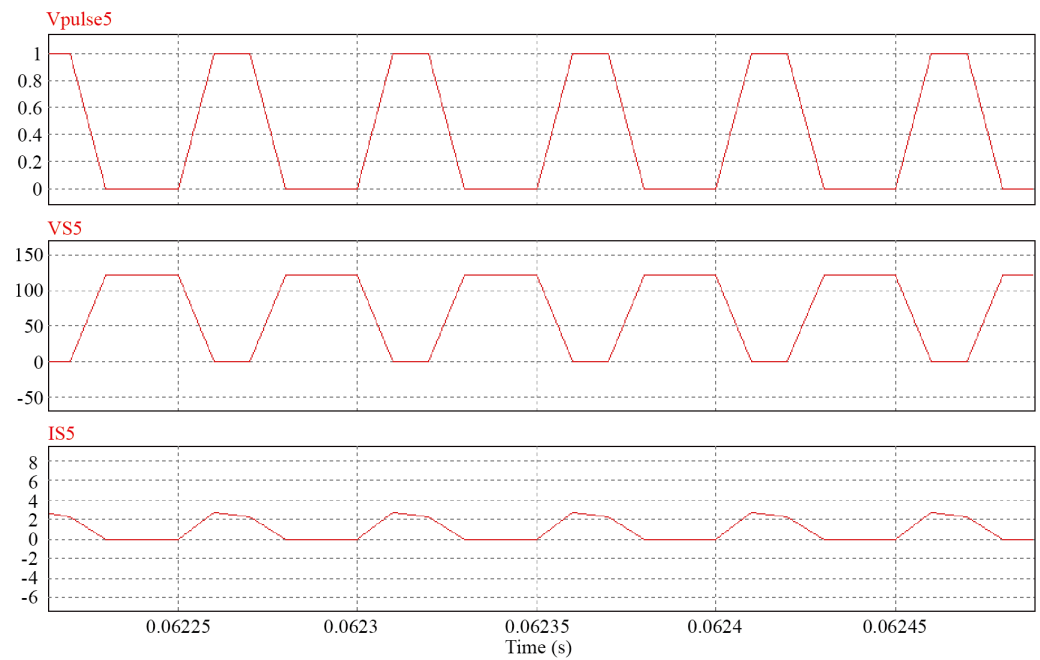

Figure 5. The switching pulses, voltage across the switch and swicth currents for S5 \& S6. 

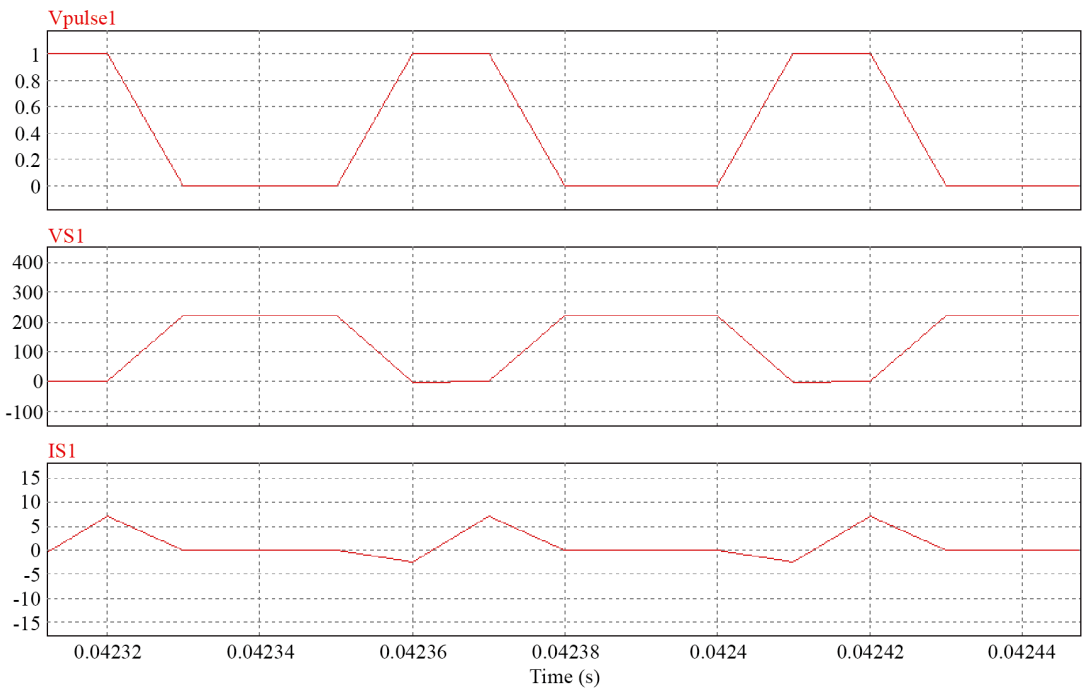

Figure 6. The switching pulses, voltage across the switch and swicth currents for S7 \& S8.
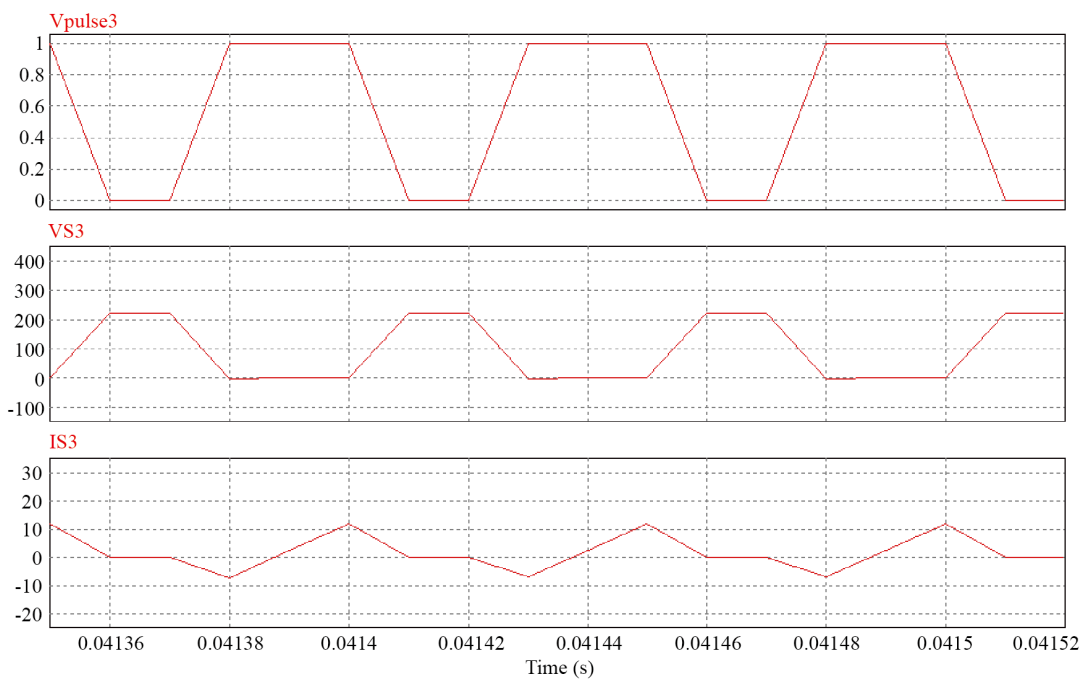

Figure 7. Zero Current Zero Voltage Switching of switches.
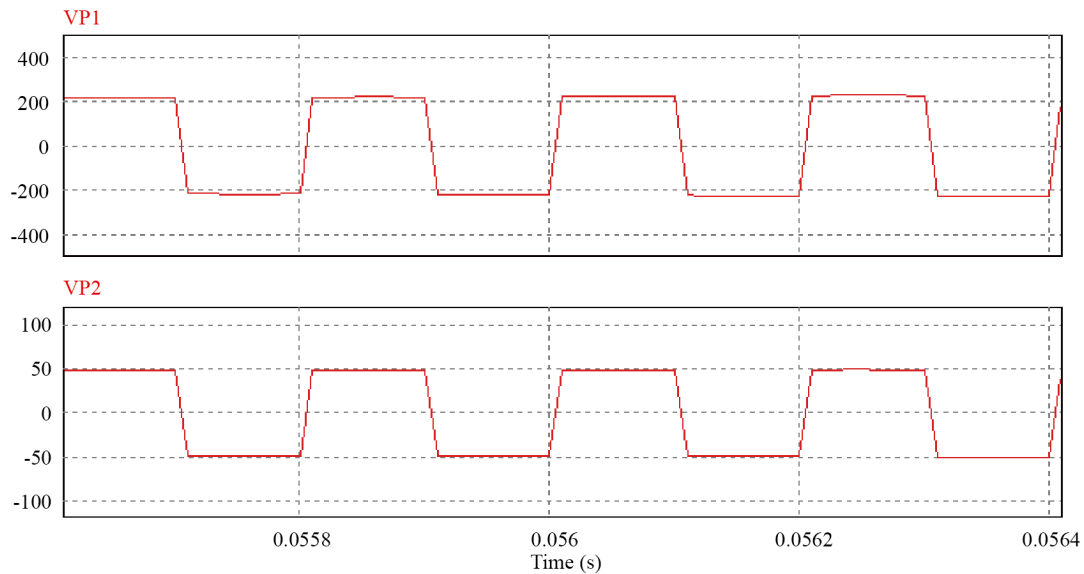

Figure 8. The two primary voltages $\mathrm{Vp} 1$ and $\mathrm{Vp} 2$. 


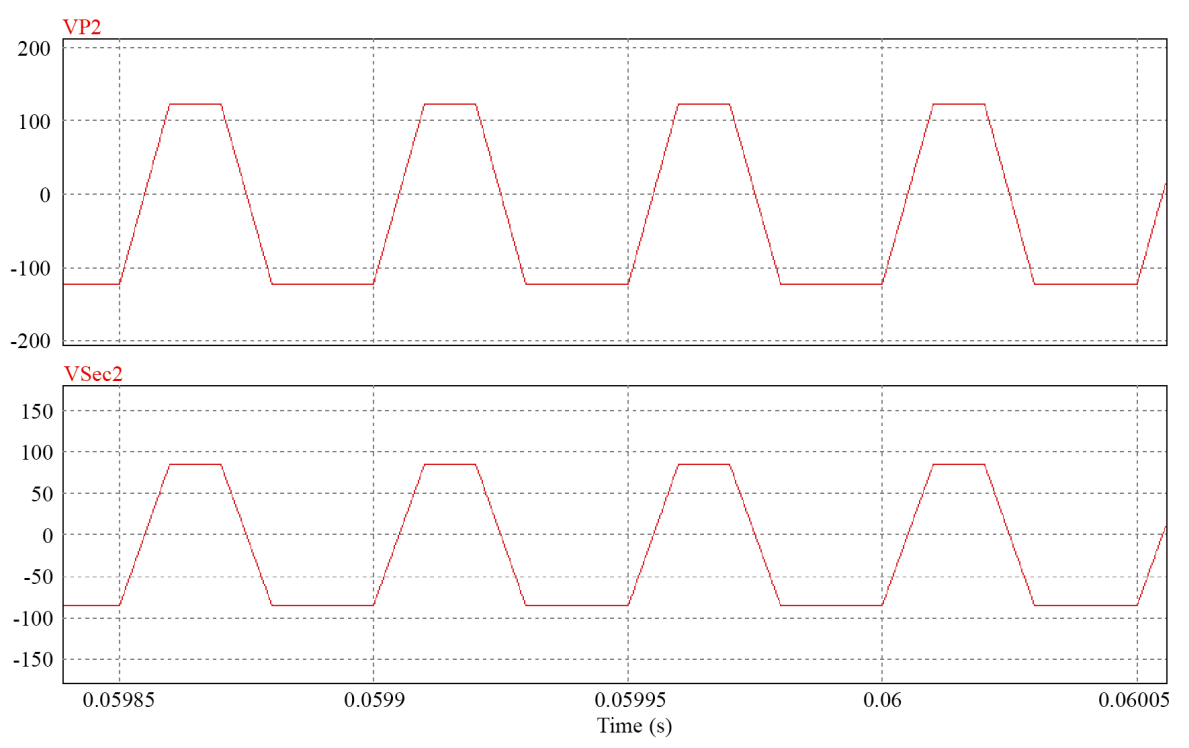

Figure 9. The two secondary voltages.

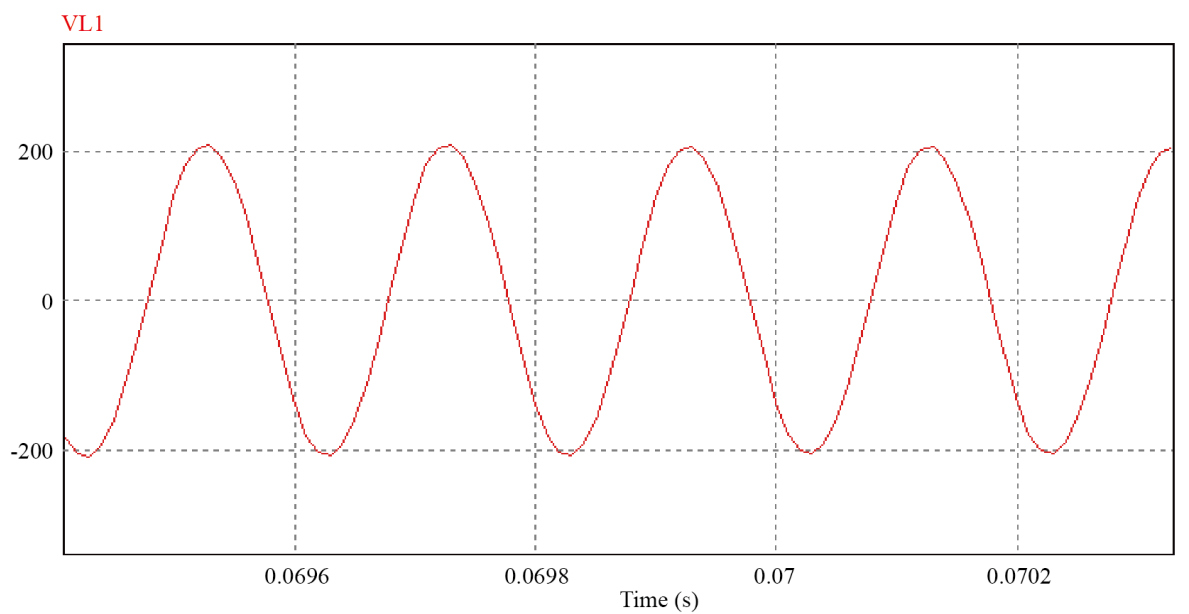

Figure 10. Load 1voltage.

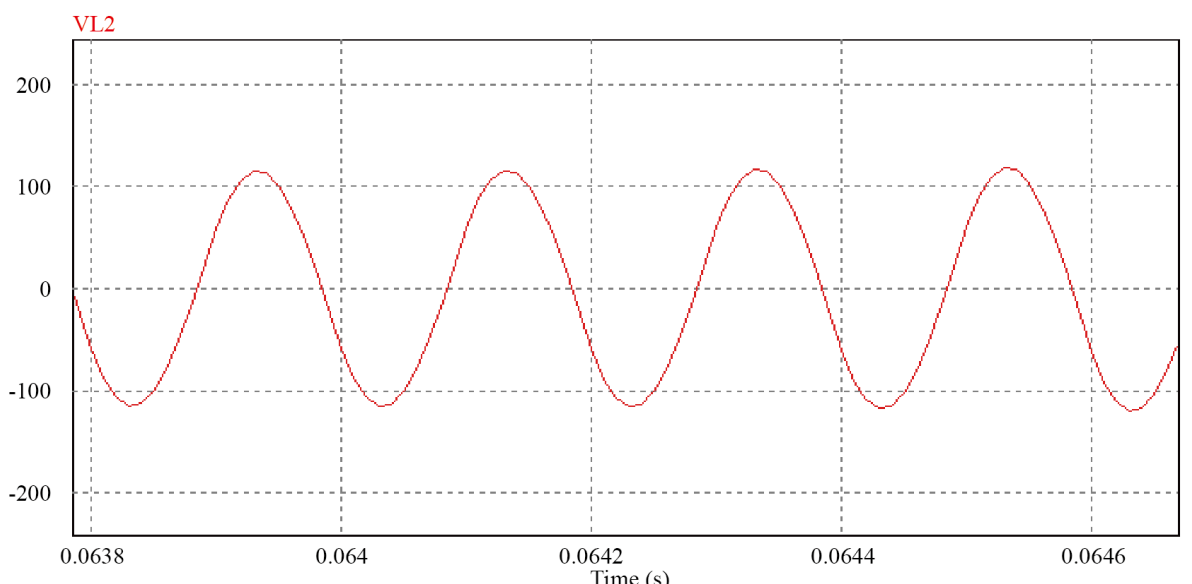

Figure 11. Load 2 voltage. 
Table 1. Simulation parameter.

\begin{tabular}{cc}
\hline Parameter & Value \\
\hline Lgf & $1 \mu \mathrm{H}$ \\
Cgf & $1000 \mu \mathrm{F}$ \\
Lpvf & $0.1 \mu \mathrm{H}$ \\
Cpvf & $1000 \mu \mathrm{F}$ \\
Switching Frequency & $5 \mathrm{kHz}$ \\
Lf1 & $10 \mu \mathrm{H}$ \\
Co1 & $10 \mu \mathrm{F}$ \\
Lf2 & $10 \mu \mathrm{H}$ \\
Co2 & $10 \mu \mathrm{F}$ \\
Load 1 & $12 \Omega$ \\
Load 2 & $12 \Omega$ \\
Grid Supply & $220 \mathrm{~V}(\mathrm{Peak})$ \\
\hline
\end{tabular}

\section{Conclusion}

A novel circuit for integrating Grid and Solar supply was proposed for two outputs. The proposed configuration has galvanic isolation. The soft switching of all the inverter switches is achieved which alleviates the switching losses. Two output voltages, which are sinusoidal, are obtained. This configuration can be further extended to get more than two outputs.

\section{References}

[1] Azmy, A.M. and Erlich, I. (2005) Impact of Distributed Generation on the Stability of Electrical Power Systems. in Proceedings of the IEEE Power Engineering Society General Meeting, Vol. 2, 1056-1063.

[2] Wu, H.F., Sun, K., Chen, R.R., Hu, H.B. and Xing, Y. (2012) Full-Bridge Three-Port Converters with Wide Input Voltage Range for Renewable Power Systems. IEEE Transactions on Power Electronics, 27, 3965-3974. http://dx.doi.org/10.1109/TPEL.2012.2188105

[3] Chen, Y.-M., Liu, Y.-C. and Wu, F.-Y. (2002) Multi-Input DC/DC Converter Based on the Multiwinding Transformer for Renewable Energy Applications. IEEE Transactions on Industry Applications, 38, 1096-1104. http://dx.doi.org/10.1109/TIA.2002.800776

[4] Matsuo, H., Lin, W., Kurokawa, F., Shigemizu, T. and Watanabe, N. (2004) Characteristics of the Multiple-Input DCDC Converter. IEEE Transactions on Industrial Electronics, 51, 625-631. http://dx.doi.org/10.1109/TIE.2004.825362

[5] Wu, H., Chen, R., Zhang, J., Xing, Y., Hu, H. and Ge, H. (2011) A Family of Three-Port Half-Bridge Converters for Stand-Alone Renewable Power System. IEEE Transactions on Power Electronics, 26, 2697-2706. http://dx.doi.org/10.1109/TPEL.2011.2125991

[6] Kobayashi, K., Matsuo, H. and Sekine, Y. (2006) Novel Solar-Cell Power Supply System Using a Multiple-Input DCDC Converter. IEEE Transactions on Industrial Electronics, 53, 281-286. http://dx.doi.org/10.1109/TIE.2005.862250

[7] Wu, H., Xu, P., Hu, H., Zhou, Z. and Xing, Y. (2014) Multiport Converters Based on Integration of Full-Bridge and Bidirectional DC-DC Topologies for Renewable Generation Systems. IEEE Transactions on Industrial Electronics, 61, 856-869. http://dx.doi.org/10.1109/TIE.2013.2254096

[8] Zeng, J., Qiao, W., Qu, L. and Jiao, Y. (2014) An Isolated Multiport DC-DC Converter for Simultaneous Power Management of Multiple Different Renewable Energy Sources. IEEE Journal of Emerging and Selected Topics in Power Electronics, 2, 70-78. http://dx.doi.org/10.1109/JESTPE.2013.2293331

[9] Gummi, L.K. and Ferdowsi, M. (2010) Double-Input DC-DC Power Electronic Converters for Electric-Drive Ve- 
hicles-Topology Exploration and Synthesis Using a Single-Pole Triple-Throw Switch. IEEE Transactions on Industrial Electronics, 57, 617-623.

[10] Zhao, R. and Kwasinski, A. (2009) Multiple-Input Single Ended Primary Inductor Converter (SEPIC) Converter for Distributed Generation Applications. Proceedings of 2009 IEEE Energy Conversion Congress and Exposition, San Jose, 20-24 September 2009, 1847-1854.

[11] Caricchi, F., Crescimbini, F., Honorati, O., Napoli, A.D. and Santini, E. (1993) Testing of a New DC/DC Converter Topology for integrated Wind Photovoltaic Generating Systems. Proceedings of 5th European Conference on Power Electronics and Applications, Brighton, 13-16 September 1993, 83-88.

[12] Bae, S. and Kwasinski, A. (2009) Maximum Power Point Tracker for a Multipleinput Ûu DC-DC Converter. Proceedings of 31st International Telecommunications Energy Conference, IEEE INTELEC 2009, 18-22 October 2009, Inchoen, 1-5.

[13] Di Napoli, A., Crescimbini, F., Guilii Capponi, F. and Solero, L. (2002) Control Strategy for Multiple Input DC-DC Power Converters Devoted to Hybrid Vehicle Propulsion Systems. Proceedings of the 2002 IEEE International Symposium on Industrial Electronics, Vol. 3, 1036-1041.

[14] Dobbs, B.G. and Chapman, P.L. (2003) A Multiple-input DC-DC Converter Topology. IEEE Power Electronics Letters, 1, 6-9. http://dx.doi.org/10.1109/LPEL.2003.813481

[15] Onar, O.C., Shirazi, O.H.A. and Khaligh, A. (2010) Grid Interaction Operation of a Telecommunications Power System with a Novel Topology for Multiple- Input Buck-Boost Converter. IEEE Transactions on Power Delivery, 25, 2633-2645. http://dx.doi.org/10.1109/TPWRD.2009.2031490

[16] Jain, S. and Agarwal, V. (2008) An Integrated Hybrid Power Supply for Distributed Generation Applications Fed by Nonconventional Energy Sources. IEEE Transactions on Energy Conversion, 23, 622-631. http://dx.doi.org/10.1109/TEC.2008.918631

[17] Kjaer, S.B., Pedersen, J.K. and Blaabjerg, F. (2005) A Review of Single-Phase Grid-Connected Inverters for Photovoltaic Modules. IEEE Transactions on Industry Applications, 41, 1292-1306. http://dx.doi.org/10.1109/TIA.2005.853371

[18] Araujo, S.V., Zacharias, P. and Mallwitz, R. (2010) Highly Efficient Single-Phase Transformerless Inverters for GridConnected Photovoltaic Systems. IEEE Transactions on Industrial Electronics, 57, 3118-3128. http://dx.doi.org/10.1109/TIE.2009.2037654

[19] Gonzalez, R., Gubia, E., Lopez, J. and Marroyo, L. (2008) Transformerless Single-Phase Multilevel-Based Photovoltaic Inverter. IEEE Transactions on Industrial Electronics, 55, 2694-2702. http://dx.doi.org/10.1109/TIE.2008.924015

[20] Kerekes, T., Liserre, M., Teodorescu, R., Klumpner, C. and Sumner, M. (2009) Evaluation of Three-Phase Transformerless Photovoltaic Inverter Topologies. IEEE Transactions on Power Electronics, 24, 2202-2211. http://dx.doi.org/10.1109/TPEL.2009.2020800

[21] Amirabadi, M., Toliyat, H.A. and Alexander, W.C. (2013) A Multiport AC Link PV Inverter with Reduced Size and Weight for Stand-Alone Application. IEEE Transactions on Industry Applications, 49, 2217-2228. 